\title{
Does Child Maltreatment Mediate Family Environment and Psychological Well-Being?
}

\author{
Michael Galea
}

University of Malta, and L.S.E.- University of London, External Program, Malta.

Email: mgalea00@yahoo.com

Received February $19^{\text {th }}, 2010$; revised April $8^{\text {th }}, 2010$; accepted April 10 $0^{\text {th }}, 2010$.

\begin{abstract}
This study tried to establish if childhood maltreatment mediates the established relationship between family environment and psychological well-being, in a sample of Maltese university students $(N=312)$. However, our analysis suggested partial mediation only. Moreover, results indicated that abusive families are less loving, socially integrated, organized, and more conflicted. Family environment contributed positively, albeit limited, to cognitive well-being after controlling for child abuse history. In particular, cohesion, do add unique variance to subjective well-being, after controlling for child abuse. This study replicates classic research on the important role that family environment plays in children's holistic development.
\end{abstract}

Keywords: Childhood Maltreatment, Family Environment, Well-Being

\section{Introduction}

The past focus on human deficiencies has only served to present a "half-baked" psychology [1]. Psychology needs to start getting seriously concerned with the qualities and experiences that make life most worthwhile. Gillham and Seligman [1] point at the sterling work of Rachman [2,3] who helped launch a systematic science of human strengths, in view of his experience with various clients with debilitating emotional disorders and past traumas. Positive psychology requires such strides to balance what has been a one-sided view of human being.

Life's crises challenge our deepest beliefs and assumptions: that good people are somehow immune of bad things, that life always makes sense, and that we are in control in whatever happens. Calhoun and Tedeschi [4] found that for most people, life's crisis ultimately lead to what he calls "post-traumatic growth". After one's basic assumptions are shattered, a new framework is constructed. Campbell, Brunch, \& Foster [5] call this phenomena "ego shock". Such negative events could potentially evaporate instantly our old habits, self-perceptions and assumptions, leaving only the raw experience of the world.

One such crisis is childhood maltreatment. Research consistently indicates a complex and difficult reality for victims of such trauma. To fully understand the impact of child abuse, key variables need be taken into consideration and evaluated for their contribution. Most impor- tantly, this paper looks at family environment, the incidence, reality, and impact of childhood abuse in Malta, and the consequences of such trauma on one's subjective well-being.

\subsection{Family Environment and Psycho-Social Development}

Studies suggest that a key variable for a child's normal development is family environment. Family environment is not just the physical aspect under which children live and grow, but also other relevant factors that affect one's developmental process, such as parental styles and dynamics. Finkelhor and Browne [6] found that the family environment was the context where most of the reported child abuse cases occur. Moreover, Finkelhor [7,8] showed that not only is the family context part of such trauma, but that the perpetrator is often known to the victims.

Scarr [9] stressed that except in extreme cases of abused and at-risk children, environmental experiences play a minimal role in influencing children's cognitive and socio-emotional development. To the contrary, Baumrind [10] found that the environment does have an important role in children's development. Thus parents should not be punitive or aloof, but promote their children with consistent rules along with considerable affection. Baumrind's argument is credible in light of attachment research. 
Bowlby [11,12] and Ainsworth [13] spoke of the importance of secure attachment in infancy for normal development. Staying in physical proximity to the primary caregiver helps the child satisfy essentials for survival, such as nourishment and self-defense. They further characterized the importance of reliable care-givers during infancy in two respects: a safe haven in times of distress and a secure base for exploring one's environment. This safety zone helps the child to develop and face life's challenges positively. The contact comfort received from such a secure environment helps the child to develop the resiliency that is critical for survival [14]. Darling and Steinberg [15] also stressed the important implications of parenting styles. Research classifies parenting styles in two directions: 1) a combination of warmth, nurturance, acceptance and responsiveness, defined by parental empathy and closeness, and 2) a demand and control family dynamic, defined by parental neglect and indifference [10]. The first parenting style is the optimal one [16].

\subsection{Child Abuse and Related Variables}

Abuse may lead to people engaging in various defense mechanisms, repressing the trauma for example so that life can move on. Dickie et al. [17] found that worse effects seem to occur when the abuser is the primary care-giver/parent. Children need to find ways to make sense of their trauma. They may internalize their guilt and feel rejected, sinful, unclean, or even ignored by a deity.

Using Bowlby's attachment theory [11], in which individuals are not passive but active in constructing and maintaining close relationships, Kirkpatrick and Shaver $[18,19]$ indicated that God may serve as a "perfect" substitute attachment figure for people with histories of avoidant attachment. Child abuse may be a potential reason for such avoidance. They speculated that the need for attachment is life-long. Kane, Cheston and Greer [20] considered this element important in that "transference might easily occur in a child's mind from father the abuser to God the Father". In related studies, spirituality but not religiosity predicted subjective well-being [21,22].

Besides attachment and spirituality, two key and related variables are family conflict and cohesion. Meyerson, Long, Miranda, and Marx [23] found that family conflict and cohesion are risk factors for the development of psychological distress and depression in adolescence, and therefore they suggest the particular study of these two variables for a more holistic appreciation and better understanding. Various researchers suggest the inclusion of other important variables when focusing on childhood maltreatment, as it never occurs in a vacuum [24,25].

Moreover, patriarchal family systems, which are prevalent in Western countries including Malta, are positively correlated to childhood maltreatment [26]. Other studies suggested the negative prediction of patriarchal systems on the well-being of family members [27,28]. This is more important in a small country like Malta, with its closely-knit family systems, and under a strong influence by a dominant Catholic faith [29,30].

\subsection{The Reality in Malta}

This study focused on the experience of childhood trauma in Malta, specifically among a sample of university students. Malta, a tiny republic island in the Mediterranean Sea, with a rich history dating back to thousands of years, has been highlighted in a recent document by the United Nations on children's welfare. The U.N. document [31] called for the urgent need for a comprehensive assessment and public policy decisions regarding this problem. Malta does not have the necessary resources to protect children from child abuse, nor any mandatory reporting laws. Galea reiterates that statistics are scarce, and child protective services are still in their infancy [22]. More awareness and research is required for better and timely response.

Galea et al. [29] surveyed Maltese university students on various aspects of childhood trauma and found that almost $11 \%$ qualified as severely abused. Interestingly, he indicated that spirituality may serve also as a potential resource in treating victims of childhood maltreatment.

To help further clarify the reality of childhood trauma, this study seeks to know whether family environment gives any additional value to well-being, after controlling other key variables, among Maltese students. The purpose of this study, therefore, was to measure the relationship and the interplay between childhood maltreatment with relevant variables, such as family environment, subjective well-being and others. This study hypothesized that the family background of victims must be conducive to abuse. Thus, such environments would correlate to high family conflict and low cohesion. Moreover, this study sought to clarify the exact nature of relationships between the key variables at play. Finally, this study intended to seek any possible mediator variable effect/s among the key variables, predicting subjective well-being.

Given the lack of relevant studies on this reality in Malta, this study could serve to further related studies among the general population, intended to highlight the incidences and relationships among such important variables to one's psycho-social well-being after trauma. As an overall summary therefore, this chapter looked at research findings on the potential implications of early attachment and family dynamics on the psycho-social well-being of young individuals.

\section{Methods}

\subsection{Participants}

The participants in this study were undergraduate stu- 
dents from the Mediterranean island of Malta. Overall, the study sampled 800 students. From a response rate of $39 \%$, there were 214 female (69\%), and 98 male respondents $(31 \%)$. The age of the participants ranged from 18 to 25 years old $($ Mean $=20.45, \mathrm{SD}=2.37)$. The religious orientation of the respondents consisted of: $97.1 \%$ Roman Catholic, $0.6 \%$ Protestant, and $2.2 \%$ no religion defined.

\subsection{Measurements}

The Family Environment Scale (FES). Developed by Moos and Moos [32], this is a 90-item, True-False instrument, paper and pencil measure intended to look at the social and environmental characteristics of families. The FES is based on a three-dimensional conceptualization of families, with related subscales: 1) Relationship, 2) Personal growth, and 3) System-Maintenance dimension. The Relationship dimension consisted of Cohesion, the degree of commitment, help, and support family members provide for one another (e.g., "Family members really help and support one another"); Expressiveness, the extent to which family members are encouraged to express their feelings directly (e.g., "We say anything we want to around home"); and Conflict, the amount of openly expressed anger and conflict among family members (e.g., "We fight a lot in our family").

The Personal Growth dimension consisted of Independence, the extent to which family members are assertive and self-sufficient, (e.g., "We think things out for ourselves in our family"); Achievement orientation, how much activities are cast into an achievement-oriented or competitive framework (e.g., "We feel it is important to be the best at whatever you do"); Intellectual-Cultural orientation, the level of interest in political, intellectual, and cultural activities (e.g., "We often talk about political and social problems"); Active-Recreational orientation, the amount of participation in social and recreational activities (e.g., "Friends often come over for dinner or to visit"); and Moral-Religious emphasis, the emphasis on ethical and religious values (e.g., "We don't say prayers in our family"). The System Maintenance dimension consisted of Organization, the degree of importance of clear organization and structure in planning family activities and responsibilities (e.g., "We are generally very neat and orderly"); and Control, how much set rules and procedures are used to run family life (e.g., "There are very few rules to follow in our family").

In this sample, alpha reliabilities for the scales constituting the three dimensions of Relationship, Personal Growth, and System Maintenance ranged from: 0.63 to $0.74,0.34$ to 0.66 , and 0.56 to 0.63 , respectively. Due to the low alphas of Personal Growth and System Maintenance dimensions in this analysis, they were removed from this study, despite their benefit in other related studies [33].
Internal consistency reliability estimates presented in the manual ranged from 0.61 to 0.78 . As for normative values, the inter-correlations among the 10 subscales ranged from -0.53 to 0.45 , suggesting that different family characteristics are measured with reasonable consistency [34]. Test-retest reliabilities were found reasonably stable across three intervals within one-year period. Face and content validity of the instrument are supported by the clear statements relating to the 10 subscale domains. Construct validity was also found through comparative descriptions of distressed and normal family samples, as shown in the manual.

Satisfaction with Life scale (SWLS). Well-being was examined from the cognitive well-being component. The Satisfaction with Life Scale (SWLS), developed by Diener, Emmons, Randy and Griffin [35], is a 5-item simple scale that measures life satisfaction and cognitive wellbeing. Pavot and Diener [36] have consistently found the internal consistencies of the SWLS and alpha coefficients as exceeding 0.80 . Test-retest correlation coefficients were found at 0.89 . The alpha reliability of the Maltese sample was found to be at 0.95 .

Childhood Trauma Questionnaire. The Childhood Trauma Questionnaire (CTQ) is a 28-item Likert-scale, which captures a history of child abuse and neglect across multiple dimensions [37]. Five subscales form the CTQ: emotional abuse, physical abuse, sexual abuse, emotional neglect, and physical neglect. The alpha reliabilities for the Maltese sample are 0.82, 0.77, 0.93, 0.83, and 0.46 respectively.

For the purpose of this study, an overall composite abuse index score was created based on the total scores of the five sub-scales. This composite score was then reciprocally transformed to meet the assumptions of normal distribution. In this sample $11 \%$ of respondents fell in the severe abuse and neglect range while $25 \%$ qualified as moderately abused. These percentages are highly similar to rates in the United States based on the studies that validated the CTQ [38].

\subsection{Procedure}

The questionnaires were mailed to participants who were randomly selected from among a pool of students who volunteer for such surveys.

\section{Results}

\subsection{Hypothesis Testing}

Table 1 presents the means, standard deviations, and alpha reliabilities for the study variables. Pearson $r$ correlations suggested that abusive families tend to be low on cohesion, expressiveness, intellectual-cultural emphasis, organization, and on moral-religiousness. These family environments seem also to be exposed to high conflict, as was hypothesized. 
Table 1. Descriptive statistics for study variables

\begin{tabular}{lccc}
\hline Variable & $\mathrm{M}$ & $\mathrm{SD}$ & Range \\
\hline Age & 20.45 & 02.37 & $18-25$ \\
Cognitive & 23.66 & 06.59 & $06-35$ \\
well-being & 3.14 & 1.32 & $0-5$ \\
Positive effect & 2.37 & 1.57 & $0-5$ \\
Negative effect & 21 & 72 & $0-5$ \\
Total abuse & 21.52 & 15.36 & $04-65$ \\
Cohesion & 46.85 & 04.47 & $38-58$ \\
Expressiveness & 62.58 & 10.77 & $33-80$ \\
Conflict & 24.43 & 13.06 & $03-53$ \\
Independence & 35.50 & 10.47 & $16-65$ \\
Achievement & 41.56 & 12.57 & $19-69$ \\
Intellectual & 47.04 & 10.72 & $23-69$ \\
Active-reactive & 42.75 & 09.30 & $27-66$ \\
Moral & 37.05 & 10.80 & $21-69$ \\
Organizational & 51.30 & 11.07 & $27-76$ \\
Control & & &
\end{tabular}

What about the family profile of a person with a history of child abuse? Abuse negatively correlated with cohesion $(r(310)=-0.40, \mathrm{p}<0.001)$, expressiveness $(r$ $(310)=-0.30, \mathrm{p}<0.001)$, intellectual-cultural orientation $(r(310)=-0.20, \mathrm{p}<0.001)$, moral-religious emphasis $(r$ $(310)=-0.22, \mathrm{p}<0.001)$, and a sense of organization $(r$ $(310)=-0.23, \mathrm{p}<0.001)$. As expected, abuse correlated positively with conflict $(r(310)=0.41, \mathrm{p}<0.001)$. Therefore, results suggest a family profile with a history of child abuse as being: low in cohesion and expressiveness, and high in conflict. These indicate a family dysfunction which evidently is not a promising and positive environment for the normal psycho-emotional development of children, let alone for those already scarred by abuse.

\subsection{Mediator Variable Effect}

The next step in our analysis concerned the main hypothesis of the study, that of the possibility of a mediator variable effect. One typically looks for mediators if there already is a strong relation between a predictor and an outcome and one wishes to explore the mechanisms behind that relation. More specifically, a mediator is defined as a variable that explains the relation between a predictor and an outcome [39]) variable. The mediator is the mechanism through which a predictor influences an outcome variable [39]. According to this method, there are four steps (performed with three regression equations) in establishing that a variable (e.g., child abuse) mediates the relation between a predictor variable (e.g., family) and an outcome variable (e.g., well-being).

Baron \& Kenny [39] explain that a variable functions as a mediator when it meets certain conditions, namely: (a) the independent variable (IV) impacts the mediator variable (MV) in the first equation (path a), (b) the IV impacts the dependent variable (DV) in the second equation (path c), (c) the MV impacts the DV in the third equation (path b), (d) if (a), (b), and (c) all hold in the predicted direction, then the effect of the IV on the DV must be less in the third equation than in the second (path c'). A perfect mediation is said to occur when this is reduced to zero. Otherwise, it is a partial mediation. The mediator variable, then, serves to clarify the nature of the relationship between the independent and dependent variables. Results are shown in Table 2.

Table 2 shows the results of the conditions sought to establish mediation. In the first equation, the independent variable (family environment) affected the mediator variable (child abuse): $r(310)=0.18, \mathrm{p}<0.001$. In the second equation, family environment impacted the outcome or dependent variable (cognitive well-being): $r$ $(310)=-0.28, p<0.001$. Child abuse impacted the out-

Table 2. Testing mediator effects using multiple regression

\begin{tabular}{|c|c|c|c|c|c|}
\hline Testing steps in mediation model & $\mathrm{B}$ & SE B & $95 \%$ & $\mathrm{CI}$ & $\beta$ \\
\hline \multicolumn{6}{|l|}{ Testing Step 1 (Path a) } \\
\hline \multicolumn{6}{|l|}{ Outcome: child abuse } \\
\hline Predictor: family environment & 0.05 & 0.01 & 0.02 & 0.07 & $0.18 * *$ \\
\hline \multicolumn{6}{|l|}{ Testing Step 2 (Path c) } \\
\hline Predictor: family environment & -0.19 & 0.04 & -0.27 & -0.12 & $-0.28 * * *$ \\
\hline \multicolumn{6}{|l|}{ Testing Step 3 (Path b and c') } \\
\hline \multicolumn{6}{|l|}{ Outcome: cognitive well-being } \\
\hline \multicolumn{6}{|l|}{ Mediator: child abuse } \\
\hline Predictor: family environment & -0.16 & 0.04 & -0.23 & -0.09 & $-0.23 * * *$ \\
\hline
\end{tabular}

Note. $\mathrm{CI}=$ Confidence Interval; $* * \mathrm{p}<0.01, * * * \mathrm{p}<0.001$ 
come variable (cognitive well-being): $r(310)=-0.23, \mathrm{p}$ $<0.001$. Results thus indicate only a partial mediation. The Statistical Mediation Model is shown in Figure 1.

The partial drop from -0.19 to -0.16 (i.e. from path $\mathrm{c}$ to c') could explain that child abuse partially mediates the relation between well-being and family. In terms of causation, a fairly strong argument can be made that family environment (predictor variable) preceded both child abuse (mediator variable) and well-being (outcome variable). However, it could be the case that individuals who are suffering from poor well-being (outcome variable) symptoms are more likely to be abused (i.e., that the outcome causes the mediator). In fact, in testing this alternative model, well-being also was a significant mediator of the relation between family and child abuse.

Thus, there are alternative models that are consistent with the data. This study also did not control for other factors that may be related to or cause both family environment and child abuse, such as key personality traits like neuroticism. Thus, all we can say at this point is that our data are consistent with models in which child abuse causes poor well-being, and poor well-being causes abuse. We also must acknowledge that the mediation relations we found might not have been evident if other variables that cause both family environment and child abuse had been included in the model. In conclusion, these results continue to indicate the relevance of family variables to well-being.

\section{Discussion}

Results indicated that child abuse as the mediator variable partially mediates the established relationship between family environment and psychological well-being. Thus, the main hypothesis of this study was partially approved.

Family environment contributed positively to cognitive well-being after controlling for child abuse history. In particular, cohesion does add unique variance to sub- jective well-being, over and above the contribution of abuse.

That dysfunctional family environments are related to childhood trauma, and to later psychological problems, is well documented in research [40,41]. Families who score on low cohesion, expressiveness, intellectual-cultural orientation, moral-religiousness, organization, and high conflict significantly correlate with child abuse and neglect. This study replicates classic studies indicating the important role the family environment plays in children's development [10,42]. Moos and Moos [34] found that abusive families are less loving, socially integrated, and organized. This finding is consistent with the conclusions of the present research.

Although some researchers [15] found a strong positive correlation between child abuse and a rigorous and strictly organized family environment, this was not supported in this study. Moreover, Moos and Moos [34] also indicated that family dysfunction defined as less supportive, socially integrated, and organized, was associated with sexual abuse. Findings in this study indicated no such links between sexual abuse and any of the Family Environment Scales. On the other hand, this study does confirm other research by Moos and Moos [34] whereby abusive families are less loving, socially integrated, and organized.

From a pastoral perspective, therapists who add to their valuable resources key family variables such as cohesion, self-expression and control, will increase their possibilities to arrive at a more holistic evaluation of their clients. This is well grounded in research $[23,40]$, as well as attachment theoretical studies $[10,13]$, as indicated previously.

Finally, repetitive family dysfunction highlighted by high levels of conflict and abuse, can create an atmosphere of learned helplessness. Abramson, Sehgman, and Teasdale [43] proposed that early experience of learned helplessness leads to a cognitive set that predisposes to later depression.

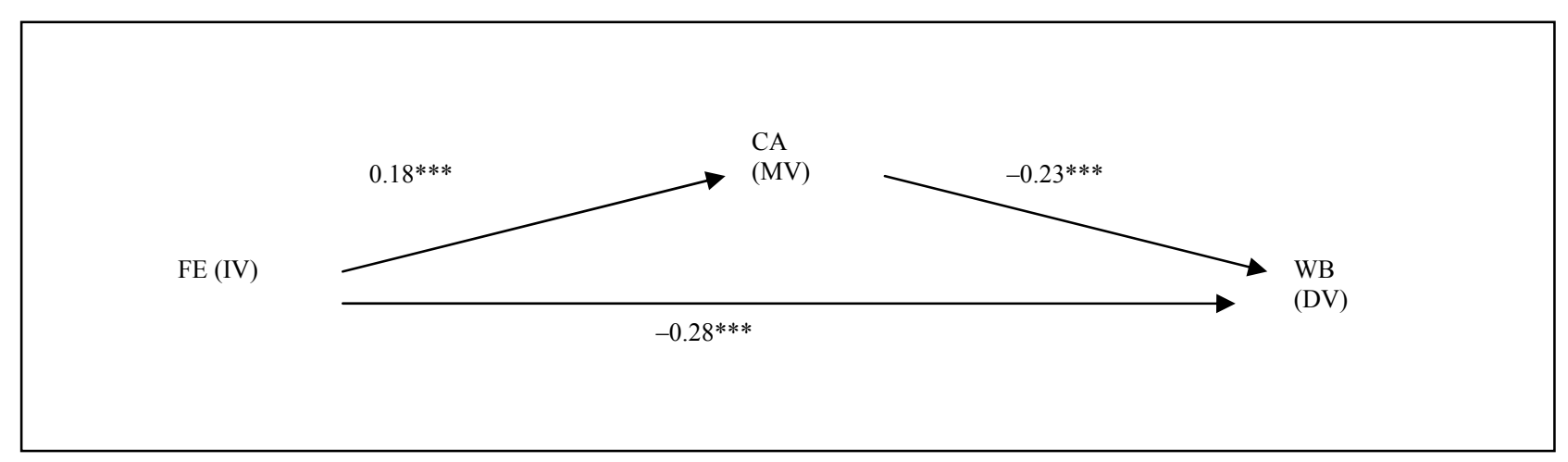

$\mathrm{N}=312 . \mathrm{FE}=$ family environment (independent variable); $\mathrm{CA}=$ child abuse (mediator variable); WB = psychological well-being (dependent variable). ${ }^{* * *} p<0.001$

Figure 1. Statistical mediation model 


\subsection{Limitations}

This study was a sample of convenience among university students. Participants were randomly selected by computer, thus containing at least one aspect of participants' self-selection. The cross-sectional nature of the design limits causal inferences. Moreover, the study's reliance upon self-reported and recalled data may have introduced sources of error. The internal reliability of the FES, a key variable measure in this research, which was used to measure family environment, was another limitation, despite opting to use only the best and highest dimension, that of Relationship, which ranged from 0.63 to 0.74 .

On the positive side, this study had a relatively large sample size, and was done in a country in which such research is still in its infancy. To this end one hopes that similar studies take the lead from this one and delve deeper into the stark reality of childhood maltreatment. Results from this study continue to confirm other related studies elsewhere on the difficulties in the psycho-social development of victims. Moreover, it continues to highlight the input given by certain variables, which would give a better picture when included in the equation.

\subsection{Conclusions}

Results from this study continue to add to the existing literature on the importance that family variables have on the psycho-emotional well-being and development of young people. This becomes clearer in view of a history of child abuse and neglect. More specifically, cohesion, emotional self-expressiveness and conflict require particular assessment, when evaluating persons with child abuse history, and when planning therapeutic programs and strategies. The study strongly suggests that the inclusion of family environment offers a better and more holistic perspective on the reality of child abuse and its consequences.

This is the next step in the Maltese scenario. Malta has long been grounded on cohesive families, supported by strong traditional and religious past. However, the effects of globalization are fast gaining pace, with not so positive consequences on such a vital cell within society. Moreover, lack of awareness of the scope of child abuse may further the weakening of the family structure, creating with it a conspiracy of silence that prevents timely action and prevention [44].

Hopefully, studies such as this one may encourage more social alertness, backed up by an appropriate legal framework to help protect victims while preventing perpetrators from pursuing their evil pursuits. It is therefore hoped that this study encourages a drive towards a deeper and more rigorous look into the aftermath of childhood trauma in a culture, which has long been overshadowed by complacency and silence. Specifically, stronger and clearer legislation, mandatory reporting laws, and availability of professional assistance and education are areas that require serious consideration. The present study can assist in educating people as to the extent, nature, and impact of child abuse in Malta. Besides protecting children, related research will continue to shed more light on the reasons and profiles of perpetrators, who should not be ignored in order to evaluate a more objective appraisal of the reality of child abuse.

Focusing the research among university students may have been the easiest to reach and study as a start. However, this study opens up an immediate requirement to further it among the general population for more appraisal of this painful reality. Child abuse is a social evil, with dire effects that shroud one's personality and emotional development. Such future research furthermore request the inclusion of key variables such as family environment and subjective-well being, in light of their close affinity to the trauma in focus

\section{REFERENCES}

[1] J. E. Gillham, K. J. Reivich, L. H. Jaycox and M. E. P. Seligman, "Prevention of Depressive Symptoms in School Children: Two-Year Follow-Up," Psychological Science, Vol. 6, No. 6, 1995, pp. 343-351.

[2] S. Rachman, "The Concept of Required Helpfulness," Behavior Research and Therapy, Vol. 17, 1979, pp. 1-6.

[3] S. Rachman, "Fear and Courage," 2nd Edition, W. H. Freeman and Co., 1999.

[4] L. G. Calhoun and R. G. Tedeschi, "The Foundations of Post-Traumatic Growth: New Considerations," Psychological Inquiry, Vol. 15, No. 1, 2004, pp. 93-102.

[5] W. K. Campbell, A. B. Brunch and J. D. Foster, "Sitting here in Limbo: Ego Shock and Posttraumatic Growth," Psychological Inquiry, Vol. 15, No. 1, 2004, pp. 22-26.

[6] D. Finkelhor and A. Browne, "The Traumatic Impact of Child Sexual Abuse: A Conceptualization," American Journal of Orthopsychiatry, Vol. 55, No. 4, 1985, pp. 530-541.

[7] D. Finkelhor, "Child Sexual Abuse: New Theory and Research," Free Press, 1984.

[8] D. Finkelhor, "Improving Research, Policy, and Practice to Understand Child Sexual Abuse," Journal of the American Medical Association, Vol. 280, No. 21, 1998. Retrieved 8 August 2001, from www.jama.amassn.org/ issues/v280n21/ffull/jed80096.html

[9] S. Scarr, "Best of Human Genetics," Contemporary Psychology, Vol. 41, 1996, pp. 149-150.

[10] D. Baumrind, "Current Patterns of Parental Authority," Developmental Psychology Monographs, Vol. 4, No. 1, P. 2, 1971 .

[11] J. Bowlby, "Attachment and Loss: Attachment," Basic Books, New York, 1969. 
[12] J. Bowlby, "Secure and Insecure Attachment," Basic Books, New York, 1989.

[13] M. D. Ainsworth, "Infant-Mother Attachment," American Psychologist, Vol. 34, No. 10, 1979, pp. 932-937.

[14] H. F. Harlow and R. R. Zimmerman, "Affectional Responses in the Infant Monkey," Science, Vol. 130, No. 3373, 1959, pp. 421-432.

[15] N. Darling and L. Steinberg, "Parenting Style as Context: An Integrative Model," Psychological Bulletin, Vol. 113, No. 3, 1993, pp. 487-496.

[16] J. A. Chambers, K. G. Power and R. C. Durham, "Parental Styles and Long Term Outcome Following Treatment for Anxiety Disorders," Clinical Psychology \& Psychotherapy, Vol. 11, No. 3, 2004, pp. 187-198.

[17] J. R. Dickie, A. K. Esleman, D. M. Merasco, A. Shepard, W. M. Vander and M. Johnson, "Parent-Child Relationships and Children's Images of God," Journal for the Scientific Study of Religion, Vol. 36, No. 1, 1997, pp. 2543.

[18] L. A. Kirkpatrick and P. R. Shaver, "An AttachmentTheoretical Approach to Romantic Love and Religious Belief," Personality and Social Psychology Bulletin, Vol. 18, No. 3, 1992, pp. 266-275.

[19] L. A. Kirkpatrick and P. R. Shaver, "Attachment Theory and Religion: Childhood Attachments, Religious Beliefs and Conversion," Journal for the Scientific Study, Vol. 29, No. 3, 1990, pp. 315-323.

[20] D. Kane, S. E. Cheston and J. Greer, "Perceptions of God by Survivors of Childhood Sexual Abuse: An Exploratory Study in an Under Researched Area," Journal of Psychology and Theology, Vol. 21, No. 3, 1993, pp. 228-237.

[21] J. W. Ciarrocchi and E. Deneke, "Happiness and the Varieties of Religious Experience: Religious Support, Practices, and Spirituality as Predictors of Well-Being," Research in the Social Scientific Study of Religion, Vol. 15, 2004, pp. 204-233.

[22] M. Galea, "The Impact of Child Abuse on the PsychoSpiritual and Religious Status of Maltese College Students," Pastoral Psychology, Vol. 57, No. 3-4, 2008, pp. 147-159.

[23] L. A. Meyerson, P. J. Long, R. Miranda and B. P. Marx, "The Influence of Childhood Sexual Abuse, Physical Abuse, Family Environment, and Gender on the Psychological Adjustment of Adolescents," Child Abuse \& Neglect, Vol. 26, No. 4, 2002, pp. 387-406.

[24] J. R. Bramblett, Jr., "A Qualitative Study of Family Dynamics and Coping Resources among Adult Male Survivors of Childhood Sexual Abuse," Dissertation Abstracts International Section A: Humanities \& Social Sciences, Vol. 59, No. 5-A, 1998, p. 1787.

[25] L. Margolin, "Child Sexual Abuse by Uncles," Child Abuse \& Neglect, Vol. 18, No. 3, 1994, pp. 215-224.

[26] S. J. Asher, "The Effects of Childhood Sexual Abuse: A Review of the Issues and Evidence," Handbook on Sexual
Abuse of Children, Springer Pub. Co., New York, 1988.

[27] J. V. Morales, "The Relative Contribution of Family Environment, Social Support, Patriarchal Values and Coping in Sexual Abuse Recovery," Dissertation Abstract International B: Sciences \& Engineering, Vol. 57, No. 1-B, 1996, p. 0704.

[28] J. M. Whealin, S. Davies, A. Shaffer, J. Jackson and L. Love, "Family Context and Childhood Adjustment Associated with Intra-Familial Unwanted Sexual Attention," Journal of Family Violence, Vol. 17, No. 2, 2002, pp. 151-165.

[29] M. Galea, J. W. Ciarrocchi, R. L. Piedmont and R. J. Wicks, "Child Abuse, Personality, and Spirituality as Predictors of Happiness in Maltese College Students," Research in the Social Scientific Study of Religion, Vol. 18, 2007, pp. 141-154

[30] M. Galea, "Incremental Validity of Extraversion among University Students in the Aftermath of Childhood Trauma," Advances in Psychology Research, Vol. 65, 2009, p. 15 .

[31] UN Convention on the Rights of the Child. Resolution: 44/25; Articles: 19, \& 37, 2000. Retrieved 10 August 2001, from http://www.unhchr.ch/html/menu3/b/k2crc. $\mathrm{htm}$

[32] R. H. Moos and B. S. Moos, "Family Environment Scale," 2nd Edition, Consulting Psychologists Press, Inc., CA, 1974-1986.

[33] C. Negy, "Assessing Family-of-Origin Functioning in Mexican American Adults: Retrospective Application of the FES," Assessment, Vol. 13, No. 4, 2006, pp. 396-405.

[34] R. H. Moos and B. S. Moos, "Family Environment Scale Manual: Development, Application, Research," 3rd Edition, Consulting Psychologists Press, Inc., CA, 1994.

[35] E. Diener, R. A. Emmons, R. J. Larsen and S. Griffin, "The Satisfaction with Life Scale," Journal of Personality Assessment, Vol. 49, No. 1, 1985, pp. 71-75.

[36] W. Pavot and E. Diener, "Review of the Satisfaction with Life Scale," Psychological Assessment, Vol. 5, No. 2, 1993, pp. 164-172.

[37] D. P. Bernstein, L. Fink, L. Handelsman, J. Foote, M. Lovejoy, K. Wenzelf, E. Sapareto and J. Ruggiero, "Initial Reliability and Validity of a New Retrospective Measure of Child Abuse and Neglect," American Journal of Psychiatry, Vol. 151, No. 8, 1994, pp. 1132-1136.

[38] D. P. Bernstein and L. Fink, "Childhood Trauma Questionnaire: A retrospective Self-Report, Manual," The Psychological Corporation, Harcourt Brace, San Antonio, 1998.

[39] R, M. Baron and D. A. Kenny, "The Moderator-Mediator Variable Distinction in Social Psychological Research: Conceptual, Strategic, and Statistical Considerations," Journal of Personality and Social Psychology, Vol. 51, No. 6, 1986, pp. 1173-1182.

[40] M. Matherne and A. Thomas, "Family Environment as a 
Predictor of Adolescent Delinquency," Adolescence, Vol. 36, No. 144, 2001, pp. 655-665.

[41] T. Hastings and J. M. Kern, "Relationships between Bulimia, Child Sexual Abuse and Family Environment," International Journal of Eating Disorders, Vol. 15, No. 2, 1994, pp. 103-111.

[42] J. M. Rey, G. Walter, J. M. Plapp and E. Denshire, "Family Environment in Attention Deficit Hyperactivity, Oppositional Defiant, and Conduct Disorders," Australian and New Zealand Journal of Psychiatry, Vol. 34, No. 3,
2000, pp. 453-457.

[43] L. Y. Abramson, M. E. P. Sehgman and J. D. Teasdale, "Learned Helplessness in Humans Critique and Reformulation," Journal of Abnormal Psychology, Vol. 87, No. 1, 1978, pp. 49-74.

[44] C. Zammit, "Children at Risk: Paper presented for Discussion at the Seminar on Child Care," Department of Family Welfare, Malta, October 1998. Retrieved 11 October 2001, from http://www.geocities.com/Athens/4185/ CarmZammit.htm 